\title{
Introduction to the Value, Success, and Performance Measurements of Knowledge, Innovation, and Entrepreneurial Systems Minitrack
}

\author{
Murray E. Jennex \\ West Texas A\&M University \\ mjennex@wtamu.edu
}

\author{
Stefan Smolnik \\ University of Hagen \\ stefan.smolnik@,fernuni-hagen.de
}

\author{
David T. Croasdell \\ University of Nevada, Reno \\ davec@unr.edu
}

Research into knowledge systems, knowledge management (KM), organizational memories, and organizational learning has been affected by investigations such as implementation aspects, system developments, or knowledge flows during a number of years. Therefore, a high maturity level of KM research has been achieved. However, organizational knowledge/KM initiatives are more and more faced with budget cuts and justification demands due to intense competition in today's business environments. The influences of the rapid pace of globalization and of the ongoing liberalization of national and international markets lead to the emergence of increased pressure on existing companies. Project managers of knowledge/KM initiatives like Chief Knowledge Officers need to justify their budgets and, thus, are in need of qualitative and quantitative evidence of the initiatives' success. In addition, ROI calculations and traditional accounting approaches do not tell an adequate story when proposing knowledge-based initiatives.

This minitrack explores research into strategies, methodologies, and stories that relate to measuring this success. In addition, this minitrack is used to explore the bodies of performance measurements that define the current state of research in measuring knowledge system, KM, organizational memory, and organizational learning success. Eventually, another purpose of this minitrack is to present research on how to value knowledge-based initiatives. Six papers were submitted and three papers are presented:

The first paper "Diversity management in organizations - the measuring of the benefits: Visegrad Group (V4) countries perspective" is co-authored by Elwira Gross-Gołacka, Marta Kusterka-Jefmańska, Bartłomiej Jefmański, Teresa Kupczyk, and Izabela Warwas. Their paper, presents the survey results of the organization representatives on the benefits of implementing the diversity management concept. The analytical part of the article is based on the survey results of 401 representatives of the organizations located in the Visegrad Group countries.
The second paper "The Limits of Open Innovation: A Literature Review and Research Agenda" is co-authored by Nan Su, Summer McGuckin, and Kaveh Abhari. Open Innovation (OI) has become a popular method of value co-creation over the past two decades. While OI offers many benefits, it holds a high failure rate. Through a systematic literature review, this paper identifies 15 common limitations of OI that contribute to this high failure rate at three levels: organizational, operational, and individual. The paper develops a framework for OI's critical success factors. This paper also offers an agenda for future research and makes contributions toward understanding OI systems and their governance from a practical standpoint.

The third paper "Scientific Approaches and Methodology to Determine the Value of Data as an Asset and Use Case in the Automotive Industry" is co-authored by Frank Bodendorf, Klaus Dehmel, and Joerg Franke. From a theoretical perspective data does not constitute a traditional business asset. Existing valuation approaches are either sector specific or still unexplored. In modern businesses the value-adding use and monetization of existing "big data" represents one of the greatest potentials in the context of digital transformation. This paper aims at reviewing methods and developing an integrated methodology for the value determination of data in general and for use in the manufacturing industry in particular. Therefore, the general state of research in data value assessment is investigated by a broad literature analysis. Based on the identified general principles, methodological requirements for data value determination are compiled. A new methodology for data evaluation is developed and applied to four use cases coming from the automotive industry.

The minitrack co-chairs want to thank authors and reviewers for their work in making this minitrack a success and we look forward to continued building of this research community in the coming years. 